Effectiveness of universal school-based programs for the primary prevention of violence in adolescents

\author{
Anna J. Gavine ${ }^{1 *}$, Peter D. Donnelly ${ }^{2}$, Damien J. Williams ${ }^{3}$ \\ ${ }^{1}$ Evidence Synthesis Training and Research Group, University of Dundee \\ ${ }^{2}$ Public Health Ontario \\ ${ }^{3}$ School of Medicine, University of St Andrews
}

*Corresponding author 


\begin{abstract}
Objective Violence is a leading cause of morbidity and mortality amongst young people. Primary preventive programs aimed at reducing the involvement of young people in violence are often implemented in a school setting. This systematic review evaluated the effectiveness of universal school-based programs aimed at the primary prevention of violence in 11-18 year olds. Method A pre-defined search strategy was used to search various sources (i.e. databases, gray literature, previous reviews, and reference lists of included studies) for randomised design trials and quasi-experimental design trials published between 2002 and March 2014. After screening 8051 abstracts, 21 studies were identified that satisfied the inclusion/exclusion criteria. These studies evaluated 16 different programs based mainly in the US. Results Due to the heterogeneity meta-analysis was not possible; thus a narrative synthesis was reported. The most effective interventions utilised social development and social norms components. Attitudes towards violence was the most frequently measured outcome with six studies reporting a beneficial effect and two reporting no effect; three of the six studies examining violent behaviour demonstrated a small beneficial effect; and four of the seven studies examining physical aggression demonstrated a small beneficial effect. Conclusions In general, this review found limited evidence of the effectiveness of universal school-based programs in the primary prevention of violence in 11-18 year olds; however, those that combined social development and social norms approaches appeared to be the most effective. Additional qualitative research/process evaluation is required to establish the processes that underpin the success/failure of such programs in order to inform their refinement, and the future development of effective programs.
\end{abstract}

Keywords: Youth Violence; Primary Prevention; social development; social norms; systematic review; evaluation. 


\section{SCHOOL-BASED VIOLENCE PREVENTION}

Violence is a leading cause of mortality and morbidity in young people (Dahlberg \& Krug, 2002) and is associated with a number of wider impacts on academic achievement and employment opportunities (Prothrow-Stith \& Davis, 2010). Moreover, exposure to violence as a child is associated with a range of health risk behaviours (e.g. smoking and alcohol consumption; Dube et al., 2003) and the development of a myriad of chronic conditions (e.g. ischaemic heart disease and cancer; Felitti et al., 1998). As many young people attend school (particularly in developed countries) a large number can be accessed with relative ease (Hahn et al., 2007). Therefore, schools represent a logical setting for violence prevention programs with adolescents (Farrell, Meyer, Kung, \& Sullivan, 2001). This paper presents a narrative systematic review of school-based violence prevention programs involving children aged 1118 years old.

Violence includes the "intentional use of physical force or power, threatened or actual, against oneself, another person, or against a group or community, that either results in or has a high likelihood of resulting in injury, death, psychological harm, maldevelopment, or deprivation" (World Health Organization [WHO],1996, p. 2-3), and has been recognised as a public health concern requiring a preventive approach (e.g. Kazdin, 2011). The World Report on Violence and Health (WRVH) which had an emphasis on primary prevention (Krug, Mercy, Dahlberg, \& Zwi, 2002), was a “catalyst for stimulating awareness and action” (WHO, 2014, p.4). Since its publication in 2002, there has been a wealth of programs aimed specifically at the primary prevention of violence for children and young people, many of which have been implemented in a school setting. As previous systematic reviews have been limited to studies published before 2005 (Derzon, Jimerson, \& Furlong, 2006; Hahn et al., 2007; Limbos, Chan, Warf, Schneir, Iverson, Shekelle, Kipke, 2007, Wilson \& Lipsey, 2007) or used programs from a defined list rather than systematically searching (Alford \& Derzon, 2012), there is a need for an updated synthesis of available evidence published after these 


\section{SCHOOL-BASED VIOLENCE PREVENTION}

systematic reviews. This review will therefore focus on studies published from 2002 onwards and should be considered in conjunction with the results of the previous reviews.

While the evidence for the primary prevention of violence is strongest for programs that are delivered in early childhood and utilise a social development approach (WHO, 2009), the onset of serious violence typically begins from the age of 12 years and peaks between 16 and 18 years (Office of the Surgeon General (US), 2001). Moreover, during adolescence, the parts of the brain (i.e. the amygdala, hypothalamus, prefrontal cortex) required for decision making, emotional regulation, behavioural inhibition and calculating outcomes of behaviour are still developing (Casey, Jones \& Hare, 2008). This can leave adolescents particularly vulnerable to risky decision making and emotional reactivity associated with violence and other health risk behaviours (Kelley, Schochet \& Landry, 2004). It is, therefore, imperative that adolescents are not neglected from the violence prevention agenda.

Schools provide access to adolescents and are one of the primary contexts for social development (Farrell et al., 2001). School-based prevention programs often target knowledge, skills, and attitudes to reduce initiation of/engagement in violence before it happens (primary/"up front" prevention; Prothrow-Stith \& Davis, 2010), and are often delivered to whole schools, year groups, or classes (rather than solely on the basis of risk), referred to as "universal" (Gordon Jr, 1983). In order to examine the effectiveness of universal schoolbased programs aimed at the primary prevention of violence (in its broadest sense, as defined by WHO, 1996) in secondary school-aged (11-18 years) young people, a systematic review was conducted to evaluate the best available quantitative evidence in the form of randomised design trials and quasi-experimental design trials. Although it is acknowledged other study designs (e.g. uncontrolled studies) may provide new insights, they are at high risk of bias and as such are generally considered to provide less reliable evidence of effectiveness. More specifically, we aim to address the following research questions: 
1. What is the impact of school-based universal primary prevention programs on violence?

2. What are the characteristics of universal primary prevention programs for violence?

3. What is the quality of the evidence for school-based primary prevention programs?

\section{Method}

\section{Search Strategy}

A detailed search was undertaken in April 2013 and updated in March 2014 to identify relevant published studies, using 9 databases: EMBASE, Medline, PsycINFO, CINAHL, Education Resources Information Centre (ERIC), Applied Social Sciences Index and Abstracts (ASSIA), Web of Knowledge, Cochrane Central Register of Controlled Trials (CENTRAL), Social, Psychological, Educational and Criminal Trials Register of the Campbell Collaboration. The databases were searched using a combination of thesaurus terms and keyword searches of titles and abstracts for three key concepts: Prevention (Program, Intervention, Prevention, Diversionary, Reduction, Initiative, Education, Population-based), Violence (Violence, Youth violence, Interpersonal violence, Aggression, Challenging behaviour, Offending, Fighting, Weapon, Knife, Firearm, Gun), and Adolescents (Under 18s, Adolescent, Youth, Teenager, Schools, Gangs). The specific search was amended as necessary for each database (to account for different search functionality). The search was limited to studies from 2002 onwards and restricted to English language papers.

To ensure no relevant studies were omitted, the reference lists of all retrieved articles and relevant systematic reviews (Hahn et al., 2007; Mytton, DiGuiseppi, Gough, Taylor, \& Logan, 2009) were also searched. Additionally, the following sources of gray literature were searched: World Health Organization: Violence Prevention Evidence Base and Resources; The World Bank; Centres for Disease Control and Prevention: Violence Prevention; National Criminal Justice Reference System; and CrimDoc.

\section{Study Selection}




\section{SCHOOL-BASED VIOLENCE PREVENTION}

After de-duplication there were 7973 records retrieved from the database search and 43 records from additional resources. Studies were included if they satisfied a set of prespecified inclusion and exclusion criteria.

Studies were considered for inclusion if they met the following five inclusion criteria: 1. sampled children and adolescents aged between 11 and 18 in full-time secondary or middle school (or international equivalent) education; 2. intervention was a universal school-based intervention that aims to reduce non-fatal violent injury, homicide, weapons possession, aggressive behaviour or pro-violent attitudes; 3 . study design was a randomised controlled trial, cluster-randomised trial, cross-over trial, quasi-randomised trials, controlled before-andafter studies with the control group being no intervention or treatment as usual, or interrupted time series design (with at least three time points before and after the intervention); 4 . as the majority of participants receiving a universal primary prevention program would not necessarily be involved in violence, it was expected that many of the studies would use predictors of later violence (Borum, 2000; Goldberg et al., 2010; Ikeda, Simon, \& Swahn, 2001) thus studies were included if they measured any of the following primary outcomes, non-fatal assaults/violent injuries (perpetration or victimization), homicide, weapon possession, incarceration due to violence, physical aggression (PA; aggressive behaviour that does not involve physical harm to another person [e.g. throwing or kicking objects]), attitudes towards violence (ATV) or non-physical aggression (NPA; the use of threatening or hostile language); 5. was a peer-reviewed publication; and 6. was published in English between 2002 and March 2014 (when updated searches were conducted).

The following six exclusion criteria were applied: 1 . interventions delivered in elementary or primary schools; school-community interventions were only included if there was a specific secondary school-based element targeting violence prevention; 2. bullying prevention programs were not included as it is considered to be a distinct form of 


\section{SCHOOL-BASED VIOLENCE PREVENTION}

interpersonal violence (Masiello \& Schroeder, 2013), defined as exposure to repeated negative actions in the context of an imbalance of power (Olweus, 1994) and has been specifically addressed elsewhere (Ferguson, San Miguel, Kilburn, \& Sanchez, 2007; Merrell, Gueldner, Ross, \& Isava, 2008); 3. interventions targeting other forms of violence involving young people (i.e. dating violence and structural violence) considered sufficiently different from youth violence to warrant distinct interventions and a separate review; 4 . interventions delivered to young people exposed to/involved in political violence, which is a form of collective violence and differs from interpersonal, youth violence; 5 . tertiary violence prevention programs (e.g. cognitive behavioural therapy) targeting young people already involved in violence, and therefore would not be considered universal prevention programs; 6. interventions targeting young people with pre-existing mental illness (e.g. oppositional defiant disorder) that put them at increased risk of violence.

All records were initially considered for relevance on the basis of title and abstract. Any irrelevant study was excluded based on the inclusion and exclusion criteria. Full text articles were obtained for all remaining records $(n=137)$ that appeared to meet the inclusion criteria or where there was insufficient information in the abstract. The full texts were then screened for eligibility. Of these 21 studies (16 different program evaluations) met the inclusion criteria and were included in the review (see PRISMA flow diagram, Appendix 1).

\section{Appraisal of Study Quality}

Risk of bias for each study was assessed using the Effective Public Health Practice Project's (EPHPP) quality assessment tool for quantitative studies (EPHPP, 2009) which has been recommended for use in systematic reviews of complex interventions (Jackson \& Waters, 2005). The tool enables users to grade a study as weak, moderate, or strong across the following domains: selection bias, study design, confounders, blinding, data collection 


\section{SCHOOL-BASED VIOLENCE PREVENTION}

methods (validity and reliability of tools), withdrawals and drop-outs, intervention integrity and analyses (e.g. unit of allocation and analysis, appropriateness of statistical methods).

\section{Results}

\section{Study Characteristics}

Although the search identified 21 papers for inclusion (see Appendix 2 for a summary) four papers reported on the same evaluation of the Aban Aya Youth Project ( Flay et al., 2004; Jagers et al., 2007; Ngwe, Liu, Flay, Segawa, \& Aban, 2004; Segawa, Ngwe, Li, \& Flay, 2005). Two papers reported on the same evaluation of the Multisite Violence Prevention Program (MVPP, 2008, 2009) two papers reported on evaluations of the Responding in Peaceful Pathways (RIPP) intervention, in urban (Farrell, Meyer, Sullivan, \& Kung, 2003a) and rural (Farrell, Valois, Meyer, \& Tidwell, 2003b) settings.

Two specific types of intervention were identified. First, social development (SD) programs that aimed to develop pro-social skills (PSS; e.g. anger management, empathy, problem-solving, communication and decision-making skills). Secondly, social norms (SN) programs that aimed to promote school wide norms for non-violence. Seven programs were stand-alone SD programs (Botvin, Griffin, \& Nichols, 2006; Castillo, Salguero, FernandezBerrocal, \& Balluerka, 2013; Espelage, Low, Polanin, \& Brown, 2013; Griffin, Holliday, Frazier, \& Braithwaite, 2009; Jiménez-Barbero, Ruiz-Hernández, Llor-Esteban, LlorZaragoza, \& Pérez García, 2013; Kliewer et al., 2011; Yeager, Trzesniewski, \& Dweck, 2013) and aimed to give students the skills to avoid violence and manage conflict peacefully (see introduction). Five studies combined SD programs with attempts to foster caring school communities which it was hoped would also create pro-social norms within the student body (Chauveron, Thompkins, \& Harel, 2012; Farrell, et al., 2003a; Farrell, et al., 2003b; Meyer, Roberto, Boster, \& Roberto, 2004; van Schoiack-Edstrom et al., 2002). Both the Aban Aya Youth Project (e.g. Flay et al., 2004) and the Multisite Violence Prevention Project (MVPP, 


\section{SCHOOL-BASED VIOLENCE PREVENTION}

2008, 2009) had an additional intervention strand that combined a SD program with family sessions for "at-risk" young people; however, as this review is focused on universal interventions, only the results from the universal program and control are included in this synthesis. Two studies utilised only a SN approach (Katz, Heisterkamp, \& Fleming, 2011; Swaim \& Kelly, 2008), which were delivered by peer mentors in an attempt to influence and change students' normative beliefs and behaviours.

There was considerable variation in the duration of the SD programs, ranging from four sessions (Kliewer et al., 2011) to four years (Flay et al., 2004). The majority SD programs utilised a combination of scenario-based, didactic and experiential activities designed to develop PSS to prevent violence. However, one program utilised expressive writing, which aimed to reduce aggressive behaviour by enhancing emotional control (Kliewer et al., 2011). Another incorporated arts-based projects to develop PSS (Chauveron et al., 2012). The SN approaches also varied considerably. Resolve It, Solve It utilised senior students to develop media campaigns to promote anti-violence SNs (Swaim \& Kelly, 2008), whereas Mentors in Violence Prevention (MVP) involved senior students taking on a leadership role and facilitating mentoring sessions with younger students (Katz et al., 2011).

The majority of programs were carried out in middle schools (students aged 12-14 years) with only three implemented in a high-school setting (Castillo et al., 2013; Katz et al., 2011; Yeager et al., 2013). It should be noted that the study by van Schoiack-Edstorm et al. (2002) comprised of an evaluation of level 1 of the program (delivered to $6^{\text {th }}$ grade students) and level 2 of the program (delivered to $7^{\text {th }}$ grade students). All studies were conducted in the US with the exception of two studies in Spain (Jiménez-Barbero et al., 2013), and one in the US and Canada (van Schoiack-Edstrom et al., 2002). Moreover, the schools tended to be located in urban settings with high levels of socioeconomic deprivation (SED), with only two studies in rural communities (Farrell, et al., 2003b; Swaim and Kelly, 2008). Finally, all studies 


\section{SCHOOL-BASED VIOLENCE PREVENTION}

utilised a cluster-controlled trial design, with the clusters either at the school- or class-level, and allocation was randomized in eight evaluations. When randomization did not occur (Castillo et al., 2008; Chauveron et al., 2012; Espelage et al., 2013; Farrell, et al., 2003a; Katz et al., 2011; Meyer et al., 2004; Swaim \& Kelly, 2008; van Schoiack-Edstorm et al., 2002) allocation was done by teacher preferences to not be a control group or school willingness to implement the program.

Only two studies (MVPP, 2008, 2009) were graded as strong using the EPHPP's tool and had a low risk of bias; however, it should be noted that the teacher-assessed outcomes in these studies were evaluated separately and graded as moderate as the teachers were not blind to the intervention status of the students. Three studies were graded as weak (Chauveron et al., 2012; Meyer et al., 2004; van Schoiack-Edstorm et al. 2002) primarily due to selection bias. Although Jagers et al. (2007) and Ngwe et al. (2004) were part of the Aban Aya project (for which all other studies were graded moderate), these studies were graded weak due to the different outcome measures used. All other studies were graded as moderate meaning they had a weak score in one domain of the assessment tool but were otherwise not at high risk of bias.

\section{Outcomes}

There was heterogeneity between studies in the methods used to measure outcomes (i.e. different scales, self-report, or school data). Moreover, follow-up varied considerably from immediately post-intervention up to 2-years. The treatment effect for each outcome is detailed in Appendix 1 and a narrative synthesis of each outcome will follow.

Violent behaviour. Evaluations of seven different interventions (Aban Aya, BRAVE, Get Real About Violence, LST, RIPP- 6, RIPP-7, Resolve It Solve it, Second Step: Student Success Through Prevention) examined the impact on the frequency of perpetration of physical violence. Four studies reported significant improvements $(p<.05)$ in self-reported 


\section{SCHOOL-BASED VIOLENCE PREVENTION}

violent behaviour (VB). First, Botvin et al. (2006) reported that the intervention group who received at least $50 \%$ of the intervention were about half as likely to be involved in frequent fighting at 6-months post-intervention. Secondly, Flay et al. (2004) reported a significantly reduced rate of increase in physical violence compared to the control groups; however, further analysis of this data by Segawa et al. (2005) identified that this effect was only found in "high risk" students, primarily because there was a floor effect in "low risk" students. Thirdly, Swaim and Kelly (2008) reported a significantly faster rate of decline in VB in intervention students. Finally, Espelage et al. (2013) reported that intervention students were significantly less likely to report violent fighting behaviour at post-test. However, although Farrell et al. (2003a) reported no significant effect at any of the follow-up periods, analysis did indicate there was a significant pre-test $\mathrm{x}$ treatment effect at 6 months using the quadratic model $(Z=2.15, p<.05)$ and at 12 months using the linear model $(Z=2.2, p<.05)$, which suggests that those with the worst pre-test scores had the biggest improvements. In addition, Griffin et al. (2009) and Meyer et al. (2004) reported no significant effects.

Physical aggression. The impact on PA was measured in six evaluations, four of which reported a significant positive effect compared to the control group $(p<.05)$. Significant positive effects in self-reported PA were reported by Botvin et al. (2006), Castillo et al. (2013) and Farrell et al. (2003b) at 9-months only. Moreover, Kliewer et al. (2011) reported a significant reduction in teacher ratings of aggression compared to controls. Conversely, Swaim and Kelly (2008) reported no significant difference in self-reported PA, and MVPP (2009) reported a small but significant increase in self-reported PA in the intervention group and slower decreases in teacher-rated PA.

Non-physical aggression. The impact on NPA was measured in six program evaluations, four of which reported a significant positive program: Botvin et al. (2006), Castillo et al., (2013) Meyer et al. (2004) and Yeager et al. (2013). However, Farrell et al. (2003s) did not 
report a significant effect on NPA in the evaluation of RIPP-7 (although there was a significant pre-test treatment group interaction at 6 months using the quadratic model $[\mathrm{Z}=$ 2.37, $\mathrm{p}<.05]$ and at 12 months using the linear model $[\mathrm{Z}=1.96, \mathrm{p}<.05])$ and Swaim and Kelly (2008) reported no significant difference in the evaluation of Resolve It, Solve It.

Victimization. Four programs measured victimization as an outcome, two of which reported a significant decrease. First, in addition to small improvements in PA, Farrell et al. (2003b) reported a small decrease at the midpoint of the intervention compared to controls; however, this was not sustained at 4- or 9-month follow-up. Secondly, while MVPP (2009) reported that the GREAT program was associated with increased PA, victimization in the universal intervention students decreased slightly over the course of the study. Furthermore, Swaim and Kelly (2008) reported a significant positive effect on verbal victimization but not physical victimization. Conversely, Griffin et al. (2009) reported no significant effect on victimization.

Violence within school. Three studies examined the effect on perceived school safety (PSS) or violence. Swaim and Kelly (2008) reported that although PSS declined in both control and intervention schools, the rate of decline was greater in the control schools. Although the GREAT program was associated with a small but significant decrease in selfreport victimization, there was no significant effect on perceived school safety (MVPP, 2009). Finally, Jimenez-Barbero et al. (2013) used perceived school violence as an outcome measure and reported significant changes in perceived playground violence by girls only.

Attitudes towards violence. Attitudes towards violence (ATV) were the most commonly measured outcome (9 evaluations) using a range of scales and measures. However, as Meyer et al. (2004) only reported on three of their twelve items in their scale (which had positive findings), the results on ATV from this study will be excluded due to risk of bias. The 


\section{SCHOOL-BASED VIOLENCE PREVENTION}

programs that utilised SD and SN approaches generally had positive impacts on beliefs and attitudes towards violence.

First, Farrell et al. (2003b) reported that compared to control students, intervention students had small but significant improvements in approval of VB at 4-month follow-up. They also found that intervention students had significantly higher approval of non-violence at 4-month and 9-month follow-up compared to control students. However, Farrell et al. (2003a) reported no positive whole group effects for ATV, although did note that there was positive effect for boys only at 12 months. Secondly, van-Schoiack-Edstorm et al. (2002) reported that both level 1 and 2 intervention students had significant reductions in proaggressive attitudes compared to controls. Thirdly, The Leadership Program's Violence Prevention Project reported positive effects in terms of intervention students having a significantly slower increase in normative beliefs about aggression compared to controls (Chauveron et al., 2012); however, it should be noted that at baseline, intervention students had significantly worse attitudes and behaviours towards violence and this study was graded as weak due to the high level of selection bias.

Of the two programs that utilised a SNs approach only, only Katz et al. (2011) used ATV as an outcome measure and reported that intervention students had significantly higher mean scores in perceived wrongfulness of aggressive behaviour compared to control students.

However, the evaluations of SD programs had more mixed effects on attitudes towards violence. Whilst Ngwe et al. (2004) demonstrated that the Aban Aya project had a significant positive effect on attitudes, Jimenez-Barbero et al. (2011) reported that the Count on Me program had no effect on attitudes. Moreover, MVPP (2008) reported students receiving the GREAT program actually had significantly higher levels of goals and strategies supportive of aggression and individual norms for non-VB. However, further analysis identified that a significant positive intervention effect on students who were at the greatest risk of violence at 


\section{SCHOOL-BASED VIOLENCE PREVENTION}

baseline (i.e. through baseline scores and parental influence) in four of the six domains measuring ATV: individual norms for aggression, $d=0.17, p=<.01$ ); goals and strategies supporting non-violent responses, $d=0.15, p=<.01$ ); beliefs fighting, $d=-0.10, p=<.05$ ); beliefs non-violent responses, $d=0.14, p=<.01$ ); conflict resolution, $d=0.14, p=<.01$

Pro-social skills. Five programs measured PSS as an outcome, however, there was considerable variation in how this was undertaken. For instance, Jagers et al. (2007) reported that the Aban Aya project was associated with less steep declines in empathy compared to the control, and Castillo et al. (2013) reported a positive effect on empathy in male students. Moreover, van Schoiack-Edstorm et al. (2002) reported that level 2 program students were less likely to perceive PSS as difficult to perform at post-test, although there was no significant effect for level 1 students. Finally, Yeager et al. (2013) measured pro-social behaviour by the percentage of students who wrote pro-social notes in the vignette and reported that three times as many incremental theory students left a note compared to control students. However, MVPP (2008) used teacher ratings of pro-social behaviour and did not find a significant program effect.

Conflict resolution skills. Six studies examined the effect of the program on conflict resolution skills (CRS)/violence avoidance, with variation in the measurement tools and mixed program effects. Chauveron et al. (2012) reported a positive program effect, with intervention students being significantly more likely to avoid conflict using pro-social verbal skills or avoidant conflict resolution strategies. Swaim and Kelly (2008) reported significant positive effects in one of the two sub-scales for measuring VB (see Appendix 1). Interestingly, while MVPP (2008) reported that there was no significant program effects on self-efficacy for non-violence at a whole group level, there was a significant positive effect for students classified as a high risk at baseline. However, Jaegers et al. (2007) reported that the program had no significant effect on self-efficacy for violence avoidance. Similarly, 
neither RIPP-6 nor RIPP-7 (Farrell et al., 2003a; Farrell et al., 2003b) had any significant effect on CRS.

\section{Discussion}

The systematic review identified 16 program evaluations comprising 21 studies that satisfied the inclusion and exclusion criteria.

\section{Impact of Universal School-based Prevention Programs on Violence}

This narrative review indicates that universal school-based primary prevention interventions may have a small effect on a number of outcomes relating to violence (i.e. reducing VB, PA, NPA, and/or pro-violent and aggressive attitudes) and the direct of effect is summarised in Table 1. In particular, the most frequently reported positive effects were for ATV and NPA. However, as the included studies explored the effectiveness of primary prevention programs (including students that would not be involved in violence), it is plausible that many of the participants would score near the lower limit on many of the outcome measures, suggesting the potential for a floor effect (Hessling, Schmidt, \& Traxel, 2003). Moreover, evaluations that conducted further analysis into mediating variables reported program effects were greater for students who were considered at high risk of violence on the basis of baseline scores (see Farrell et al., 2003a; MVPP, 2008; Segawa et al., 2005). Although these effects were only measured on a short-term basis (i.e. until the end of the school year or end of the following school year), this suggests that a more efficient use of resources may be in targeting prevention violence programs rather than deliver them universally.

\section{Characteristics of Universal School-based Violence Prevention Programs}

This review found that the majority of the programs are underpinned by the SD model, which proposes that antisocial and pro-social behaviour can be predicted by the presence of risk and protective factors (Catalano, Kosterman, Hawkins, Newcomb, \& Abbott, 1996). The 


\section{SCHOOL-BASED VIOLENCE PREVENTION}

SD model integrates control theory and social learning theory and emphasises the importance of bonds with pro-social family, school, and peers (Hawkins, Catalano, \& Miller, 1992). According to the model, interventions that aim to enhance protective factors can reduce the effects of risk factors and result in positive outcomes instead of health-risk behaviours (Hawkins, Catalano, Kosterman, Abbott, \& Hill, 1999). More specific to violence prevention, SD programs aim to help young people develop protective factors in the form of PSS and attitudes intolerant of violence, which enable them to develop and maintain healthy relationships and acquire the skills necessary to deal with conflict and solve problems without resorting to violence (WHO, 2009).

While attitudes and skills are important considerations, it is recognised that SN play an influential role in human behaviour (Ajzen, 1991). Such approaches may be particularly effective with secondary school-age students as they are often influenced by their peers with regards participation in a range of health risk behaviours (Wood, Read, Mitchell, \& Brand, 2004). Moreover, Prothrow-Stith and Davis (2010) argue that as SN are such powerful determinants of behaviour, they must be addressed by violence prevention programs (see also Neville, 2015). Indeed, a number of programs in this review focused primarily on changing SN by recruiting senior students to model acceptable behaviour (Katz et al., 2011, Swaim \& Kelly, 2008). The evaluations identified some success in challenging culturally held beliefs that violence is an acceptable means to resolve conflict.

In addition to the uni-dimensional approaches, a number of programs adopted a dual approach combining SD and SN approaches, which were found to have the greatest success in reducing pro-violent and pro-aggressive attitudes (Chauveron et al., 2012; Farrell et al., 2003b; Van-Schoiack-Edstorm et al., 2002). Indeed, the Spectrum of Prevention identifies the development of individual skills and knowledge (SD approach) and a change in SN (SN approach) as the most effective way of promoting healthy behaviour (Cohen \& Chehimi, 


\section{SCHOOL-BASED VIOLENCE PREVENTION}

2010). Appendix 3 provides a logic model of how SD programs can be combined with SN approaches to reduce violence in school students, based on the papers in this review.

With the exception of the SN programs (Katz et al., 2011; Swaim \& Kelly, 2008) which were delivered by students and Count on Me (Jimenez-Barbero et al., 2013), Get Real about Violence (Meyer et al., 2004), LST (Botvin et al., 2006), Second Steps (van SchoiackEdstorm et al., 2002) and Second Step (Espelage et al., 2013), which were delivered by teachers, all other programs were delivered by external staff. These tended to either be postgraduate students, psychologists, trained health educators or prevention specialists or former teachers. As the larger program evaluations (e.g. GREAT, RIPP) used external staff, it is difficult to draw any firm conclusions as to whether usual teaching staff or external staff were associated with greater program effects. Programs varied considerably in terms of duration with the shortest program being only 4 sessions (Kliewer et al., 2011) and the longest lasting four years (Flay et al., 2004). However, the majority of programs tended to last between 12 and 20 sessions. Interestingly, there was no clear association between program duration and effect.

It is also worth considering if (and how) violence prevention programs have changed since the publication of the World Report on Violence and Health (Krug et al., 2002). An examination of the included studies of previous systematic reviews (e.g. Hahn et al., 2007; Limbos et al., 2007; Wilson \& Lipsey, 2007) identified that the universal prevention programs utilised social skills development and knowledge/information sessions as the intervention strategy, whereas the current review also identified studies that aimed to change social norms (either in conjunction with SD programs or as standalone programs) towards violence. In addition, this review highlights the increase in publication of research on schoolbased violence prevention programs and crucially the number of programs that have outcome evaluations. For instance, running our same search in MEDLINE identified almost 4 times as 
many records published from 2002 onwards compared to studies published prior to 2002 . Indeed, Wilson and Lipsey (2007) noted that since 2003 there has been an increased emphasis on schools to implement evidence-based programs.

\section{Quality of the Evidence for School-based Primary Prevention Programs}

The majority of the studies were at risk of bias having been graded as either moderate or weak, indicating that study quality was generally poor. The exception was GREAT (MVPP, 2008, 2009) which was graded strong on all aspects apart from the teacher-completed data and interestingly showed the weakest program effects. The origins of the potential bias varied. First, lack of randomisation resulting in selection bias was an issue in three of the studies (Chauveron et al., 2012; Meyer et al., 2004; van Schoiack-Edstorm et al., 2002). A further two studies used assignment methods that were not truly random but were at less risk of selection bias (Farrell et al., 2003a; Katz et al., 2011). Secondly, as teachers were aware of the allocation status of participants, teacher-rated data would be susceptible to bias. Thirdly, the fact that some schools were only willing to participate if they received the intervention and would not act as a control group highlights the difficulty of randomisation in evaluation of complex violence prevention programs. Finally, the use of self-report data from questionnaires, can have implications for the reliability of the findings; however, as the majority of participants were not involved in violence at all or at the level of violence requiring the attention of healthcare providers or the criminal justice system, the use of official statistics would not be appropriate as they would be unlikely to detect change in the short follow-up periods used by most of the studies.

\section{Limitations}

In addition to the limitations associated with the risk of bias inherent in the included studies, there two specific limitations associated with the review process itself that need to be considered when interpreting the findings of this review. First, limiting the analysis to only 


\section{SCHOOL-BASED VIOLENCE PREVENTION}

articles in English increased the risk of language bias, particularly as some articles were found, and subsequently excluded, in other languages, including: German (Schick \& Cierpka, 2009), Spanish (Lopez \& Meyer, 2006), French (Tremblay, 2010), and Korean (Park, 2008). Secondly, there is considerable location bias as only four of the evaluations were conducted outwith the US (i.e. Spain, Canada, and Australia). The generalizability of these findings must, therefore, be questioned, particularly to low- or middle-income countries, which shoulder the greatest burden of violence, and experience a relative paucity of violence research.

\section{Research Implications}

This systematic review provided an up-to-date narrative synthesis of the best available evidence on the effectiveness of school-based programs for the primary prevention of violence. The review indicated that despite the increasing number of programs being implemented, effect sizes (when positive) tended to be modest. Moreover, there is a lack of evidence examining sustainability of effects, with follow-up ceasing at the end of the school year or when the students graduate or leave school. This indicates that little progress has been made since the reviews of Hahn et al. (2007) and Wilson and Lipsy (2007) almost ten years ago. Given the resources and financial costs needed to sustain such programs and the apparent absence of a large and sustained effect (possibly in part due a floor effect), it is important to reflect upon whether or not universal school-based primary prevention programs are the most (cost-)effective approach.

In order to progress this field of research, it is argued that instead of simply conducting more outcome evaluations, researchers need to engage with the young people receiving these interventions and conduct process evaluations, which as noted can provide an understanding of why an intervention may succeed or fail (Williams, Gavine, Ward \& Donnelly, 2015). Indeed, this approach has recently been utilised in an evaluation of the Seconds Steps 
program (Farrell, Mehari, Mays, Sullivan, \& Le, 2015) and found that while students generally seemed to enjoy the program and were able to identify positive outcomes that had happened using the skills learned, 34-53\% identified negative outcomes across the skills. Process evaluations such as this are therefore crucial in informing future programs (see Williams \& Neville, in press).

However, before concluding that an intervention is ineffective it is important to consider the appropriateness of the evaluation framework (Williams et al., 2015). For instance, a oneoff evaluation (e.g. Second Steps) is unlikely to develop a full appreciation of the impact of the program; whereas an evaluation that considers a wide range of outcomes (i.e. Aban Aya) is more likely to identify where the impact of a program is located. Nonetheless, an understanding of why an intervention has "succeeded"/"failed" can only really be developed through a process evaluation, involving qualitative research methods (Williams et al., 2015). The combination of quantitative (outcome evaluation) and qualitative methods (process evaluation) can inform the refinement and development of effective violence prevention programs.

Furthermore, research is needed outwith the US, particularly in low- and middle-income countries to establish whether such interventions would have a positive effect in different settings. For instance, the Aban Aya youth project (Flay et al., 2004) was developed around the African-American culture, and may not successfully transfer to another context. This is particularly important as violence prevention programs may be culture- or context-specific and require informed refinement prior to implementation.

\section{Clinical and Policy Implications}

The systematic review found that school-based primary prevention initiatives predominantly adopted a SD approach, which tended to have a small but significant effect on a range of outcomes, particularly in students with higher baseline scores. Whilst such 


\section{SCHOOL-BASED VIOLENCE PREVENTION}

programs aimed to reduce youth violence specifically, they may also have wider impacts on other forms of violence (e.g. intimate partner violence, bullying, etc.) that are favoured by some of the same risk factors. Likewise it is feasible, that interventions specifically aimed at reducing these other forms of violence (e.g. bullying interventions in school settings) may also be effective in reducing youth violence. Nonetheless, the absence of a large, sustained effect may reflect the difficulties in changing individuals' attitudes (Ajzen, 2001). The use of a social norms approach may encourage change in (mis-)perceptions and/or behaviour by challenging prevailing norms around violence (Neville, 2015). Thus, multi-component initiatives that combine both SD and social norms approaches may offer the greatest impact in preventing violence among school-aged young people. Importantly, in order to affect sustained change it would be necessary to meaningfully engage with the students themselves to help refine such programs to ensure relevance to the issues they face (Williams et al., 2014). Moreover, given the increasing prevalence of school-based violence prevention programs, thorough evaluation is necessary to assess if and how they achieve their stated aims and whether they represent appropriate allocation of limited resource, but also that they do not cause harm. 


\section{References}

Ajzen, I. (1991). The Theory of Planned Behavior. Organizational Behavior and Human Decision processes, 50(2), 179-211.

Ajzen, I. (2001). Nature and operation of attitudes. Annual Review of Psychology, 52(1), 2758.

Alford, A. A., \& Derzon, J. (2012). Meta-analysis and systematic review of the effectiveness of school-based programs to reduce multiple violent and antisocial behavioral outcomes. In S. Jimerson, A. Nickerson, M. J. Mayer, \& M. J. Furlong (Eds.), Handbook of school violence and school safety: International research and practice ( $2^{\text {nd }}$ ed., pp. 593-606). New York, NY: Routledge.

Borum, R. (2000). Assessing violence risk among youth. Journal of Clinical Psychology, $56(10), 1263-1288$.

Bosworth, K., Espelage, D., DuBay, T., Daytner, G., \& Karageorge, K. (2000). Preliminary evaluation of a multimedia violence prevention program for adolescents. American Journal of Health Behavior, 24(4), 268-280.

Botvin, G., Griffin, K., \& Nichols, T. (2006). Preventing youth violence and delinquency through a universal school-based prevention approach. Prevention Science, 7(4), 403-408.

Casey, B. J., Jones, R. M., \& Hare, T. A. (2008). The adolescent brain. Annals of the New York Academy of Sciences, 1124(1), 111-126.

Castillo, R., Salguero, J. M., Fernandez-Berrocal, P., \& Balluerka, N. (2013). Effects of an emotional intelligence intervention on aggression and empathy among adolescents. Journal of Adolescence, 36(5), 883-892.

Catalano, R. F., Kosterman, R., Hawkins, J. D., Newcomb, M. D., \& Abbott, R. D. (1996). Modeling the etiology of adolescent substance use: A test of the social development model. Journal of Drug Issues, 26(2), 429. 


\section{SCHOOL-BASED VIOLENCE PREVENTION}

Chauveron, L. M., Thompkins, A. C., \& Harel, O. (2012). Urban youth violence prevention: effectiveness of a scaled-up practice-to-research program. Journal of Children's Services, 7(4), 246-261.

Cohen, L., \& Chehimi, S. (2010). The imperative for primary prevention. In L. Cohen, V. Chavez, \& S. Chemini (Eds.), Prevention is primary: Strategies for community well-being (pp. 3-31). San Francisco, CA: Jossey-Bass.

Dahlberg, L., \& Krug, E. G. (2002). Violence: A global public health problem. In E. G. Krug, L. Dahlberg, J. Mercy, A. B. Zwi, \& R. Lozano (Eds.), World report on violence and health. Retreived from World Health Organization website: http://www.who.int/violence_injury_prevention/violence/world_report/en/full_en.pdf?ua= 1.

Derzon, J., Jimerson, S. R., \& Furlong, M. (2006). How effective are school-based violence prevention programs in preventing and reducing violence and other antisocial behaviors? A meta-analysis. In S. Jimerson, A. Nickerson, M. J. Mayer, \& M. J. Furlong (Eds.), Handbook of school violence and school safety: From research to practice (pp. 429-441). New York, NY: Routledge..

Dube, S. R., Felitti, V. J., Dong, M., Chapman, D. P., Giles, W. H., \& Anda, R. F. (2003). Childhood abuse, neglect, and household dysfunction and the risk of illicit drug use: The adverse childhood experiences study. Pediatrics, 111(3), 564-572.

EPHPP. (2009). Effective Public Health Practice Project: Quality assessment tool for quantitative studies. Retrieved from http://www.ephpp.ca/tools.html

Espelage, D. L., Low, S., Polanin, J. R., \& Brown, E. C. (2013). The impact of a middle school program to reduce aggression, victimization, and sexual violence. Journal of Adolescent Health, 53(2), 180-186. 


\section{SCHOOL-BASED VIOLENCE PREVENTION}

Farrell, A. D., Mehari, K., Mays, S., Sullivan, T. N., \& Le, A.-T. (2015). Participants’ perceptions of a violence prevention curriculum for middle school students: Was it relevant and useful? Journal of Primary Prevention, 36(4), 227-46.

Farrell, A. D., Meyer, A. L., Kung, E. M., \& Sullivan, T. N. (2001). Development and evaluation of school-based violence prevention programs. Journal of Clinical Child Psychology, 30(2), 207-220.

Farrell, A. D., Meyer, A. L., Sullivan, T. N., \& Kung, E. M. (2003a). Evaluation of the Responding in Peaceful and Positive Ways (RIPP) seventh grade violence prevention curriculum. Journal of Child and Family Studies, 12(1), 101-120.

Farrell, A. D., Valois, R. F., Meyer, A. L., \& Tidwell, R. P. (2003b). Impact of the RIPP violence prevention program on rural middle school students. Journal of Primary Prevention, 24(2), 143-167.

Felitti, V. J., Anda, R. F., Nordenberg, D., Williamson, D. F., Spitz, A. M., Edwards, V., .. . Marks, J. S. (1998). Relationship of childhood abuse and household dysfunction to many of the leading causes of death in adults: The Adverse Childhood Experiences (ACE) Study. American Journal of Preventive Medicine, 14(4), 245-258.

Ferguson, C. J., San Miguel, C., Kilburn, J. C., \& Sanchez, P. (2007). The effectiveness of school-based anti-bullying programs: A meta-analytic review. Criminal Justice Review, $32(4), 401-414$.

Flay, B. R., Graumlich, S., Segawa, E., Burns, J. L., Holliday, M. Y., \& Aban Aya, I. (2004). Effects of 2 prevention programs on high-risk behaviors among African American youth: A randomized trial. Archives of Pediatrics \& Adolescent Medicine, 158(4), 377-384.

Goldberg, A. J., Toto, J. M., Kulp, H. R., Lloyd, M. E., Gaughan, J. P., Seamon, M. J., \& Charles, S. P. (2010). An analysis of inner-city students' attitudes towards violence before and after participation in the. Injury, 41(1), 110-115. 


\section{SCHOOL-BASED VIOLENCE PREVENTION}

Gordon Jr, R. S. (1983). An operational classification of disease prevention. Public Health Reports, 98(2), 107.

Griffin, J. P., Holliday, R. C., Frazier, E., \& Braithwaite, R. L. (2009). The BRAVE (Building Resiliency and Vocational Excellence) Program: Evaluation findings for a career-oriented substance abuse and violence preventive intervention. Journal of Health Care for the Poor and Underserved, 20(3), 798-816.

Hahn, R., Fuqua-Whitley, D., Wethington, H., Lowy, J., Crosby, A., Fullilove, M., . . Dahlberg, L. (2007). Effectiveness of universal school-based programs to prevent violent and aggressive behavior: A systematic review. American Journal of Preventive Medicine, 33(2, Suppl. 1), S114-S129.

Hawkins, J. D., Catalano, R. F., Kosterman, R., Abbott, R., \& Hill, K. G. (1999). Preventing adolescent health-risk behaviors by strengthening protection during childhood. Archives of Pediatrics \& Adolescent Medicine, 153(3), 226-234.

Hawkins, J. D., Catalano, R. F., \& Miller, J. Y. (1992). Risk and protective factors for alcohol and other drug problems in adolescence and early adulthood: Implications for substance abuse prevention. Psychological Bulletin, 112(1), 64-105.

Hessling, R., Schmidt, T., \& Traxel, N. (2003). Floor effect. In M. Lewis-Beck, A. E. Bryman, \& T. F. Liao (Eds.), The SAGE encyclopedia of Social science research methods (Vol. 1, pp. 390-391). London: SAGE Publications

Ikeda, R. M., Simon, T. R., \& Swahn, M. (2001). The prevention of youth violence: The rationale for and characteristics of four evaluation projects. American Journal of Preventive Medicine, 20(1), 15-21.

Jackson, N., \& Waters, E. (2005). Criteria for the systematic review of health promotion and public health interventions. Health Promotion International, 20(4), 367-374. 


\section{SCHOOL-BASED VIOLENCE PREVENTION}

Jagers, R. J., Morgan-Lopez, A. A., Howard, T. L., Browne, D. C., Flay, B. R., \& Aban Aya, C. (2007). Mediators of the development and prevention of violent behavior. Prevention Science, 8(3), 171-179.

Jiménez-Barbero, J. A., Ruiz-Hernández, J. A., Llor-Esteban, B., Llor-Zaragoza, L., \& Pérez García, M. (2013). Efficacy of a brief intervention on attitudes to reduce school violence: A randomized clinical trial. Children and Youth Services Review, 35(9), 1313-1318.

Katz, J., Heisterkamp, H. A., \& Fleming, W. M. (2011). The social justice roots of the mentors in violence prevention model and its application in a high school setting. Violence Against Women, 17(6), 684-702.

Kazdin, A. E. (2011). Conceptualizing the challenge of reducing interpersonal violence. Psychology of Violence, 1(3), 166-187.

Kelley, A. E., Schochet, T., \& Landry, C. F. (2004). Risk taking and novelty seeking in adolescence: Introduction to part I. Annals of the New York Academy of Sciences, 1021(1), 27-32.

Kliewer, W., Lepore, S. J., Farrell, A. D., Allison, K. W., Meyer, A. L., Sullivan, T. N., \& Greene, A. Y. (2011). A school-based expressive writing intervention for at-risk urban adolescents' aggressive behavior and emotional lability. Journal of Clinical Child and Adolescent Psychology, 40(5), 693-705.

Krug, E. G., Dahlberg, L. L., Mercy, J. A., Zwi, A. B., Lozano, R. (2002). World report on violence and health. Retreived from World Health Organization website: http://www.who.int/violence_injury_prevention/violence/world_report/en/full_en.pdf?ua= 1.

Limbos, M. A., Chan, L. S., Warf, C., Schneir, A., Iverson, E., Shekelle, P., \& Kipke, M. D. (2007). Effectiveness of interventions to prevent youth violence: A systematic review. American Journal of Preventive Medicine, 33(1), 65-74. 


\section{SCHOOL-BASED VIOLENCE PREVENTION}

Lopez, T. M., \& Meyer, R. (2006). Cops and Docs: St Clare Hospital's strategy for educating teens about the medical and legal consequences of violence. Journal of Emergency Nursing, 32(5), 432-434.

Masiello, M. G., \& Schroeder, D. (Eds.). (2013). A public health approach to bullying prevention. Washington, DC: American Public Health Association.

Merrell, K. W., Gueldner, B. A., Ross, S. W., \& Isava, D. M. (2008). How effective are school bullying intervention programs? A meta-analysis of intervention research. School Psychology Quarterly, 23(1), 26-42.

Meyer, G., Roberto, A. J., Boster, F. J., \& Roberto, H. L. (2004). Assessing the Get Real About Violence curriculum: Process and outcome evaluation results and implications. Health Communication, 16(4), 451-474.

MVPP. (2008). The multisite violence prevention project: Impact of a universal school-based violence prevention program on social-cognitive outcomes. Prevention Science, 9(4), 231. MVPP. (2009). The ecological effects of universal and selective violence prevention programs for middle school students: A randomized trial. Journal of Consulting and Clinical Psychology, 77(3), 526-542.

Mytton, J. A., DiGuiseppi, C., Gough, D., Taylor, R. S., \& Logan, S. (2009). School-based secondary prevention programs for preventing violence (Review). Cochrane Database of Systematic Reviews (3). Retreived from http://onlinelibrary.wiley.com/doi/10.1002/14651858.CD004606.pub2/epdf

Neville, F. (2015). Preventing violence through changing social norms. In P. Donnelly \& C. Ward (Eds.), Oxford textbook of violence prevention: Epidemiology, evidence and policy (pp. 239-244). Oxford: Oxford University Press. 


\section{SCHOOL-BASED VIOLENCE PREVENTION}

Ngwe, J. E., Liu, L. C., Flay, B. R., Segawa, E., \& Aban, A. (2004). Violence prevention among African American adolescent males. American Journal of Health Behavior, 28(Suppl 1), S24-37.

Office of the Surgeon General (US). (2001). Youth violence: A report of the Surgeon General. Retreived from http://www.ncbi.nlm.nih.gov/books/NBK44294/

Olweus, D. (1994). Bullying at school. New York, NY: Springer.

Orpinas, P., Kelder, S., Frankowski, R., Murray, N., Zhang, Q., \& McAlister, A. (2000). Outcome evaluation of a multi-component violence-prevention program for middle schools: the Students for Peace project. Health Education Research, 15(1), 45-58.

Park, H. S. (2008). The development of an integrated suicide violence prevention program for adolescents. Journal of Korean Academy of Nursing, 38(4), 513-521.

Prothrow-Stith, D., \& Davis, R. A. (2010). A public health approach to preventing violence. In L. Cohen, V. Chavez, \& S. Chehimi (Eds.), Prevention is primary: Strategies for community well-being (2nd ed., pp. 323-350). San Francisco, CA: Jossey-Bass.

Schick, A., \& Cierpka, M. (2009). Violence prevention in secondary schools: The Faustloscurriculum for middle school. [German] Gewaltpravention in Weiterfuhrenden Schulen: Das Faustlos-Curriculum fur die Sekundarstufe. Praxis der Kinderpsychologie und Kinderpsychiatrie, 58(8), 655-671.

Segawa, E., Ngwe, J. E., Li, Y., \& Flay, B. R. (2005). Evaluation of the effects of the Aban Aya Youth Project in reducing violence among African American adolescent males using latent class growth mixture modeling techniques. Evaluation Review, 29(2), 128-148.

Swaim, R. C., \& Kelly, K. (2008). Efficacy of a randomized trial of a community and schoolbased anti-violence media intervention among small-town middle school youth. Prevention Science, 9(3), 202-214. 


\section{SCHOOL-BASED VIOLENCE PREVENTION}

Tremblay, R. E. (2010). Adolescent violence: Prevent rather than punish. Psychiatrie Sciences Humaines Neurosciences, 8(2), 57-60.

van Schoiack-Edstrom, L., Frey, K. S., \& Beland, K. (2002). Changing adolescents' attitudes about relational and physical aggression: An early evaluation of a school-based intervention. School Psychology Review, 31(2), 201-216.

Williams, D. J., Gavine, A. J., Ward, C. L., \& Donnelly, P. D. (2015). What is evidence in violence prevention? In P. Donnelly \& C. Ward (Eds.), Oxford textbook of violence prevention: Epidemiology, evidence and policy (pp. 125-131). Oxford: Oxford University Press.

Williams D. J., \& Neville, F. G. (in press). Qualitative evaluation of Mentors in Violence Prevention pilot in Scottish high schools. Psychology of Violence.

Wilson, S. J., \& Lipsey, M. W. (2007). School-based interventions for aggressive and disruptive behavior: Update of a meta-analysis. American Journal of Preventive Medicine, 33(2), S130-S143.

Wood, M. D., Read, J. P., Mitchell, R. E., \& Brand, N. H. (2004). Do parents still matter? Parent and peer influences on alcohol involvement among recent high school graduates. Psychology of Addictive Behaviors, 18(1), 19-30.

WHO (1996). WHA49.25 Prevention of violence: A public health priority. Retreived from http://www.who.int/violence_injury_prevention/resources/publications/en/WHA4925_eng .$p d f$

WHO. (2009). Violence prevention the evidence. Retreived from http://apps.who.int/iris/bitstream/10665/77936/1/9789241500845_eng.pdf?ua=1

WHO. (2014). Global status report on violence prevention 2014. Retreived from http://www.who.int/violence_injury_prevention/violence/status_report/2014/report/report/ en/ 
Yeager, D. S., Trzesniewski, K. H., \& Dweck, C. S. (2013). An implicit theories of personality intervention reduces adolescent aggression in response to victimization and exclusion. Child Development, 84(3), 970-988. 